[RADIOCARBON, VOL 28, No. 2A, 1986, P 266-278]

\title{
GEOMAGNETIC-HELIOMAGNETIC MODULATION OF ATMOSPHERIC RADIOCARBON PRODUCTION
}

\author{
PAUL E DAMON and TIMOTHY W LINICK
}

Laboratory of Isotope Geochemistry, Department of Geosciences University of Arizona, Tucson, Arizona 85721

\begin{abstract}
New Arizona high precision $\Delta^{14} \mathrm{C}$ data back to $6500 \mathrm{BC}$ plot close to an $11,300-\mathrm{yr}$ period sinusoid extrapolated from the post $5300 \mathrm{BC}$ data (offset $=+32 \%$, half amplitude $=51 \% 0$ and phase lag $=2.29$ radians). The trend curve is modulated by high latitude tude $=51 \%$ and phase lag $=2.29$ radians). The trend curve is modulated by high latitude
components of the non-dipole field with a fundamental period of $2400 \mathrm{yr}$. Based upon a model of Lund and Banerjee (1985), the non-dipole field rotates and every $1200 \mathrm{yr}$ the high latitude maxima pass over the north magnetic pole and near the south magnetic pole in reversed polarity. This modulates cosmic ray production producing extended maxima ca $\mathrm{AD}$ $1700,700 \mathrm{BC}, 3100 \mathrm{BC}$, and $5500 \mathrm{BC}$. The 2400 period appears to be stationary. The magnetic field also modulates the amplitude of the solar activity induced cycles of periods 200,80 , and $11 \mathrm{yr}$ as can be seen in the Zürich-Bern Camp Century ice core data as well as in the $\Delta^{14} \mathrm{C}$ fluctuation data. Reinterpretation of the Camp Century ${ }^{10} \mathrm{Be}$ data indicates that it is in agreement with magnetic field as well as solar activity modulation of terrestrial radioisotope production.
\end{abstract}

\section{INTRODUCTION}

At the time of the Twelfth Nobel Symposium, 16 years ago, three major causes of atmospheric ${ }^{14} \mathrm{C}$ fluctuations were identified and discussed (Olsson, 1970). These were astrophysical effects, in particular, solar modulation of the ${ }^{14} \mathrm{C}$ production rate, geophysical effects, specifically changes in the earth's magnetic field, and climate effects involving changes in carbon reservoir parameters and exchange rates.

Recent reviews of archaeomagnetic and rock magnetic data suggest an increase of the virtual axial dipole moment (VADM) by ca $60 \%$ from ca 5500 to $2300 \mathrm{BP}$ followed by a decrease to the present value of close to $8.0 \times 10^{22} \mathrm{Am}^{2}$ (Barton, Merrill \& Barbetti, 1979; Champion, 1980). Magnetic data prior to $5500 \mathrm{BP}$ are scarce, mainly limited to Japan and Europe, and do not definitively support the alleged sinusoidal variation of the dipole field (Barton, Merrill \& Barbetti, 1979). In addition to changes in the dipole field intensity, the magnetic data are affected by dipole wobble, changes in intensity of the nondipole field and the westward drift of the nondipole field. During the last century, the main nondipole centers have moved to the west by ca $0.18^{\circ} / \mathrm{yr}$ on the average according to Strangway (1970) and, more recently, $0.15^{\circ} / \mathrm{yr}$ according to Lund and Banerjee (1985).

Secular variations of atmospheric ${ }^{14} \mathrm{C}$ concentration with a time scale of decades to a few centuries and amplitudes up to $2 \%$ were first reported by de Vries $(1958,1959)$. These secular variations, called the "de Vries effect" by Damon and Long (1962), have been amply confirmed (see Damon, Lerman \& Long, 1978, for documentation). Stuiver (1961, 1965) was the first to show a convincing relationship between the de Vries effect fluctuations and solar activity and subsequent work has served only to confirm his conclusions (Damon, Lerman \& Long, 1978). Indeed, ${ }^{14} \mathrm{C}$ is produced by secondary neutrons resulting from cosmic ray induced spallation and it is well known that solar activity modulates the cosmic ray intensities reaching the earth (Lingenfelter \& Ramaty, 1970) and so there can be no doubt that ${ }^{14} \mathrm{C}$ production varies with solar activity. 
The influence of climate on the ${ }^{14} \mathrm{C}$ concentration has often been discussed, most recently and quantitatively by Siegenthaler, Heimann and Oeschger (1980). These authors demonstrate that purely physico-chemical effects such as changes in the volume and surface temperature of the oceans are not significant. This conclusion was previously reached by Damon (1970). Siegenthaler, Heimann and Oeschger (1980) point out that biologic effects, such as may have occurred during major climatic fluctuations like transition from glacial to interglacial climates, may have been more important. Biologic changes must be drastic and occur over a short period of time to produce measurable effects. For example, they demonstrate that a doubling of the biopshere from 50 to $100 \%$ of its present size would result in an increase in $\Delta^{14} \mathrm{C}$ from $0.4 \%$ to $1 \%$ if the biosphere grew linearly during $500 \mathrm{yr}$ but would increase to $2 \%$ if the change took place within 100 years. Drastic changes in the atmosphere-ocean $\mathrm{CO}_{2}$ exchange flux or in ocean circulation would also measurably change the concentration of atmospheric ${ }^{14} \mathrm{C}$. For example, they suggest that a $20 \%$ increase in the worldwide wind velocity over the ocean would increase the $\mathrm{CO}_{2}$ transfer velocity by $50 \%$ implying a decrease of $2 \%$ in atmospheric ${ }^{14} \mathrm{C}$ concentration. A change in the global formation of deep ocean water represented by a decrease or increase of eddy diffusion by a factor of two would lead to an atmospheric ${ }^{14} \mathrm{C}$ change by $+10.4 \%$ or $-5.5 \%$, respectively. Siegenthaler, Heimann and Oeschger (1980, p 190) conclude "it appears improbable that the observed ${ }^{14} \mathrm{C}$ wiggles (de Vries effect) could have been caused by fluctuating exchange rates."

\section{SECULAR VARIATIONS OF ATMOSPHERIC RADIOCARBON DURING THE LAST SEVEN MILLENNIA}

Prior to the Tenth International Radiocarbon Conference held in August 1979, there were 1200 measurements on dendrochronologically dated tree-ring samples, principally Pinus longaeva and Sequoia gigantea (bristlecone pine and giant sequoia) from the southwestern United States (Klein et al, 1980). A data set comprised of these 1200 measurements was detrended by logarithmic compression and polynomial regression. After the data were detrended, the residuals of the data around the trend were analyzed by a Fourier regression technique in overlapping intervals of 500 yr. The data were then winsorized, welded, and recombined with the trend to form a ${ }^{14} \mathrm{C}$ fluctuation curve. The effectiveness of the Fourier regression to retrieve real signals from a noisy data set was then tested against artificial data as well as the two sets of high precision data then available in the literature (de Jong, Mook \& Becker, 1979; Stuiver \& Quay, 1980). The results verified the remarkable effectiveness of the method. Additional high precision results have been reported but are not yet available (Pearson $\&$ Baillie, 1983; Pearson, Pilcher \& Baillie, 1983).

The signal retrieved from the 1200 analyses and reported by Klein $e t$ al (1980) is plotted in Figure 1. The parameters of the sinusoidal trend curve are offset $=32 \% 0$, half amplitude $=51 \%$, period $=11,300 \mathrm{yr}$ and phase lag $=2.29$ radians $\left(131.1^{\circ}\right)$. This period and amplitude are identical to that reported by Bruns et al (1983) based on La Jolla ${ }^{14} \mathrm{C}$ dating of dendrochron- 


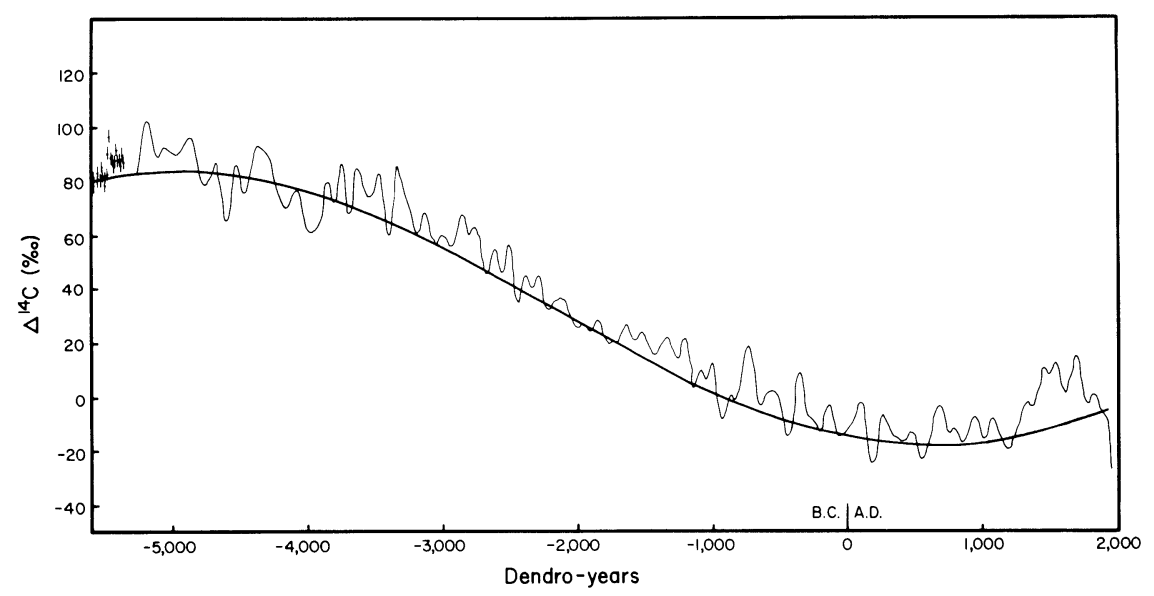

Fig $1 .{ }^{14} \mathrm{C}$ fluctuation curve based on 1200 measurements of dendrochronologicallydated tree rings from laboratories reported in Damon et al (1980); Klein et al (1980). The trend curve is an 11,300 yr sinusoid. Note the ca 200-yr period de Vries effect (Suess wiggles) resulting from solar modulation. A 2400 -yr period is expressed by extended maxima following the minimum at $\mathrm{AD} 1100$ to present, $800 \mathrm{BC}$ to $\mathrm{AD} 100$, and $3800 \mathrm{BC}$ to $2800 \mathrm{BC}$.

ologically-dated bristlecone pine and a floating European oak series. The Maunder minimum $\left({ }^{14} \mathrm{C}\right.$ maximum) can be seen at AD 1700 , the Spörer minimum at $\mathrm{AD} 1500$, and the Wolf minimum at AD 1300. These peaks are beautifully resolved in the high-precision data of Stuiver and Quay (1980). It is noteworthy that the Spörer minimum is further split by two peaks of lower amplitude $80 \mathrm{yr}$ apart. The minima are each $200 \mathrm{yr}$ apart. A $150-200-\mathrm{yr}$ periodicity was first reported by Willis, Tauber and Münnich (1960) for variations over the past $1300 \mathrm{yr}$ and Damon, Long and Grey (1966) suggested a periodicity of $200 \mathrm{yr}$. However, it was only through the persistent efforts of Hans Suess over several decades that this periodicity has been clearly demonstrated and extended over the last seven millennia (Suess, 1980). The persistence of this ca 200-yr periodicity has been shown to extend over the entire 8500-yr La Jolla record by Sonett (1984). We have used the Burg maximum entropy method (Burg, 1975) to search for higher frequencies in the MEM power spectra of the composite data set. Periodicities of 80 and $100 \mathrm{yr}$ persist with a lag of 200 and prediction error filters (PEF) of 25, 75, and 100 as well as with a lag of 400 and PEF of 25, 50, and 100. The $80-\mathrm{yr}$ periodicity is identical with the 80 -yr solar cycle in auroral frequency numbers observed by Gleissberg (1965). The Fourier power spectrum of the oxygen isotope record from Camp Century ice shows dominant frequencies of 78 and 181 yr (Johnsen, Dansgaard \& Clausen, 1970).

Houtermans (1971) developed a technique for calculating the Fourier power spectrum of unequally spaced data and employed the method on the La Jolla ${ }^{14} \mathrm{C}$ data covering the last seven millennia. He found significant periodicities at $2350 \pm 100 \mathrm{yr}, 1300 \pm 35 \mathrm{yr}, 420 \pm 15 \mathrm{yr}$, and $210 \pm 10 \mathrm{yr}$. Wallick, working in this laboratory, used the Blackman-Tukey method on 
the same data set and obtained significant periodicities at $2320 \mathrm{yr}, 1160 \mathrm{yr}$, $540 \mathrm{yr}, 250 \mathrm{yr}$, and $200 \mathrm{yr}$. Less significant peaks were observed at $410 \mathrm{yr}$, $180 \mathrm{yr}$, and $100 \mathrm{yr}$. A very strong 2400 -yr peak is also observed in the composite data set discussed earlier. Sonett (1984) has also shown that the 200 -yr periodicity in the La Jolla data persists over the 8500-yr La Jolla record and appears to be associated with an intense longer period, $2080+680$. Although Sonett makes little of it, the most intense short period peak $(>100<400)$ in the MEM derived spectrum is $180 \mathrm{yr}$. Sonett also confirms the lack of stationarity in the medium to short period spectra (100-500-yr period; see also Damon, 1977, Table 5, p 439).

Some of these periods have also been observed in other than ${ }^{14} \mathrm{C}$ data. For example, Cohen and Lintz (1974) find evidence for periodicities of $179,89.6,11.2$, and $9.8 \mathrm{yr}$ in the sunspot data from AD 1793-1971 with the 179 -yr period being a beat phenomenon rather than primary excitation. In addition to the periodicities of $78 \mathrm{yr}$ and $181 \mathrm{yr}$, previously mentioned, Dansgaard et al (1971) find evidence for a persistent period of ca $350 \mathrm{yr}$ in the Greenland ice core oxygen record for the last ten millennia and a significant periodicity of ca $2000 \mathrm{yr}$ back to $45,000 \mathrm{BP}$. Finally, Lund and Banerjee (1985) find evidence for a fundamental wave length of $2400 \mathrm{yr}$ with harmonics at 1200, 800, and 600 yr for secular variation of the last Quaternary paleomagnetic field. According to Lund and Banerjee (1985, p 821), "the fundamental wavelength of 2,400 years is very noteworthy because that is the estimated time for the nondipole field to rotate $360^{\circ}$ due to westward drift."

Our analysis (Fig 1) indicates large positive deviations of $\Delta^{14} \mathrm{C}$ ca $\mathrm{AD}$ $1700,700 \mathrm{BC}$, and $3300 \mathrm{BC}$. These positive fluctuations are also observable in the longer La Jolla data set including south German oak samples and also ca 5500 BC. It seems that it is no coincidence that these major past deviations from the trend curve occur every ca $2400 \mathrm{yr}$. Allowing for the appropriate lag time between magnetic minimum and ${ }^{14} \mathrm{C}$ maximum of $230 \mathrm{yr}$ (Siegenthaler, Heimann \& Oeschger, 1980; Damon, Sternberg \& Radnell, 1983), the dipole and major nondipole would have been in anticoincidence at $\mathrm{AD} 1470,930 \mathrm{BC}, 3330 \mathrm{BC}$, and $5730 \mathrm{BC}$.

\section{SIMULATION OF THE RADIOCARBON FLUCTUATION CURVE}

In order to simulate the $\Delta^{14} \mathrm{C}$ variations around the 11,300 -yr sinusoidal trend curve and demonstrate the effect of modulation by the earth's magnetic field, we have chosen the nondipole paleomagnetic drift period of $2400 \mathrm{yr}$ and harmonics. We have also chosen solar periods of $200 \mathrm{yr}$, $80 \mathrm{yr}$, and $11 \mathrm{yr}$, and assumed that their amplitudes are modulated by an 11,300-yr dipole magnetic field plus the westward drifting major nondipole field components (Lingenfelter \& Ramaty, 1970; Damon, 1977). The resulting equation has the form:

$$
\begin{aligned}
\Delta^{14} \mathrm{C}(\% 00)=\mathrm{A}_{\mathrm{i}=0}+\sum_{\mathrm{i}}\left[\mathrm{A}_{\mathrm{i}} \sin \left(\omega_{\mathrm{i}} \mathrm{t}-\zeta_{\mathrm{i}}\right)\right] & \\
& +\sum_{\mathrm{j}, \mathrm{k}}\left[\left(\mathrm{A}_{\mathrm{j}}+\mathrm{A}_{\mathrm{k}} \sin \left(\omega_{\mathrm{k}} \mathrm{t}-\zeta_{\mathrm{k}}\right)\right) \sin \left(\omega_{\mathrm{j}} \mathrm{t}-\zeta_{\mathrm{j}}\right)\right]
\end{aligned}
$$


where the $\mathrm{A}_{\mathrm{i}}, \omega_{\mathrm{i}}$, and $\zeta_{\mathrm{i}}$ refer to the amplitudes, frequencies and phase lags of the magnetic components; the $A_{\mathrm{j}}, \omega_{\mathrm{j}}$ and $\zeta_{\mathrm{j}}$ are the corresponding values for the solar periodicities whose amplitudes, $\mathrm{A}_{\mathrm{j}}$, are also modulated with an amplitude of $A_{k}$ by the magnetic field variations. The data are shown in Table 1.

Figure 2 presents the results of the evaluation of Eq 1 from AD 1820 to 5300 BC. Large, extended, positive deviations of $\Delta^{14} \mathrm{C}$ occur ca AD 1700 , $700 \mathrm{BC}$, and $3300 \mathrm{BC}$, as expected, despite the strong attenuation by the high magnetic dipole field assumed to peak at 300 BC. However, the solar activity induced peaks (SAIP) are subdued on either side of the early $\mathrm{BC}$ maximum in both the smoothed data curve and in the simulated data as anticipated by the high intensity of the dipole field. The SAIP are not subdued on the early BC side of the $3100 \mathrm{BC}$ maximum as a predicted result of the lower dipole magnetic field (in both figures). Also average values remain below the 11,300-yr trend curve from 3800-4800 BC in both figures, again in agreement with the drifting 2400-yr magnetic cycle. These features can also be seen very clearly in the spline-fitted data of Bruns $e t$ al (1983, Fig 1). The simulated data nicely reproduce the Medieval Warm Epoch minimum at $\mathrm{AD} 1100$ and the $\Delta^{14} \mathrm{C}$ maxima at the Wolf, Spörer and Maunder minima. Furthermore, the reality of the ca 200 -yr periodicity in the smoothed data set is evidenced by the near coincidence of major ca 200 year period maxima and minima in the two figures with a few exceptions where significant phase shifts occur. Exceptions can be seen at $900 \mathrm{BC}$, $2700 \mathrm{BC}$, and $3700 \mathrm{BC}$.

TABLE 1

Parameters used in simulating the $\Delta^{14} \mathrm{C}(\% 0)$ atmospheric fluctuation curve

\begin{tabular}{|c|c|c|c|c|c|c|c|c|c|}
\hline \multirow{2}{*}{$\begin{array}{c}\text { Period }\left(\mathrm{T}_{\mathbf{i}}\right) \\
(\mathrm{yr})\end{array}$} & \multicolumn{3}{|c|}{$\begin{array}{r}\text { Frequencies } \\
\text { (degrees/yr) }\end{array}$} & \multicolumn{2}{|c|}{ Amplitude } & $(\% \circ)$ & \multicolumn{3}{|c|}{ Phase lags (degrees) } \\
\hline & $\omega_{i}$ & $\omega_{j}$ & $w_{k}$ & $\mathrm{~A}_{i}$ & $\mathrm{~A}_{j}$ & $\mathrm{~A}_{\mathrm{k}}$ & $\zeta_{i}$ & $\zeta_{j}$ & $\zeta_{\mathrm{k}}$ \\
\hline Steady State & & & & 37.0 & & & & & \\
\hline 11,300 & 0.03186 & & & 46.0 & 0.0 & 0.0 & $+131 \cdot 1$ & & \\
\hline 2,400 & 0.1500 & & & 7.0 & 0.0 & 0.0 & -52.5 & & \\
\hline 1,200 & 0.3000 & & & 3.6 & 0.0 & 0.0 & -15.0 & & \\
\hline 800 & 0.4500 & & & 1.8 & 0.0 & 0.0 & +202.5 & & \\
\hline 600 & 0.6000 & & & 1.0 & 0.0 & 0.0 & +240.0 & & \\
\hline 11 & & 32.7273 & & 0.0 & 1.0 & 0.0 & & +2528.0 & \\
\hline$(200)_{j}(11,300)_{k}$ & & 1.8000 & 0.03186 & 0.0 & 9.0 & 3.0 & & +360.0 & +161.7 \\
\hline$(200)_{j} \quad(2,400)_{k}$ & & 1.8000 & 0.1500 & 0.0 & 9.0 & 1.5 & & +360.0 & -18.6 \\
\hline$(200)_{j} \quad(1,200)_{k}$ & & 1.8000 & 0.3000 & 0.0 & 9.0 & 0.5 & & +360.0 & +7.8 \\
\hline$(80)_{\mathrm{j}}(11,300)_{\mathrm{k}}$ & & 4.5000 & 0.03186 & 0.0 & 5.0 & 1.5 & & +1035.0 & +162.7 \\
\hline$(80)_{j} \quad(2,400)_{k}$ & & 4.5000 & 0.1500 & 0.0 & 5.0 & 0.75 & & +1035.0 & -13.6 \\
\hline
\end{tabular}




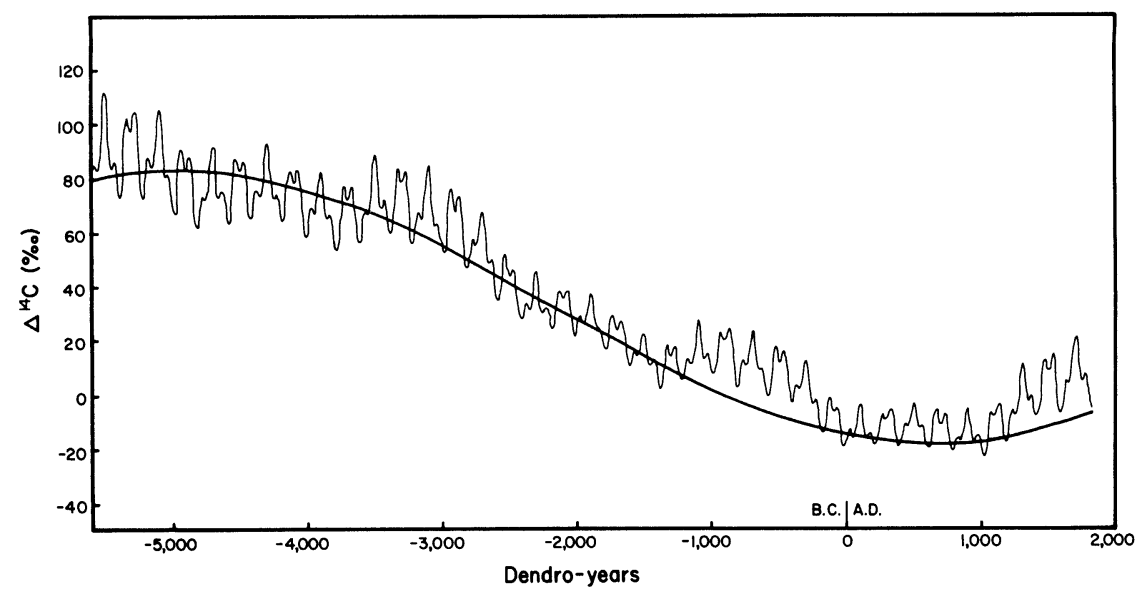

Fig 2. Simulation of the ${ }^{14} \mathrm{C}$ fluctuation curve by solar cycles of 200 and 80 -yr periods and magnetic cycles of $11,300 \mathrm{yr}$ for the earth's magnetic dipole moment and $2400 \mathrm{yr}$ plus weak harmonics $(1200,800$, and $600 \mathrm{yr})$ by the non-dipole field. The magnetic components also modulate the amplitude of the solar cycles to produce larger solar cycle fluctuations when the dipole and non-dipole field are less intense and a dampening effect when the magnetic components are more intense. The dampening effect can be seen on either side of the 2400-yr extended maximum of $\Delta^{14} \mathrm{C}(1100-200 \mathrm{BC})$ where both the dipole and non-dipole field are more intense. The Medieval Warm Epoch minimum occurs at AD 1100 and the Wolf, Spörer and Maunder minima $\left(\Delta^{14} \mathrm{C}\right.$ maxima) occur at $\mathrm{AD} 1300, \mathrm{AD} 1500$, and $\mathrm{AD} 1700$. The Spörer minimum peak is split by the 80 -yr cycle ( $c f$ Fig 1 ).

Figure 3 extends the simulated data to $8000 \mathrm{BC}$ to show the postulated maxima ca $5500 \mathrm{BC}$ and $7900 \mathrm{BC}$, and Figure 4 detrends the data to show the $2400,1200,200$ and 80-yr modulation of the trend. Detrended data sets show a similar, but not as symmetric, pattern (Klein et al, 1980, Fig 2; Suess, 1980, Fig 1). In addition to measurement error, the non-regularity could result from non-stationarity of the higher harmonics of the westward paleomagnetic drift. The 2400 fundamental period appears to be stationary.

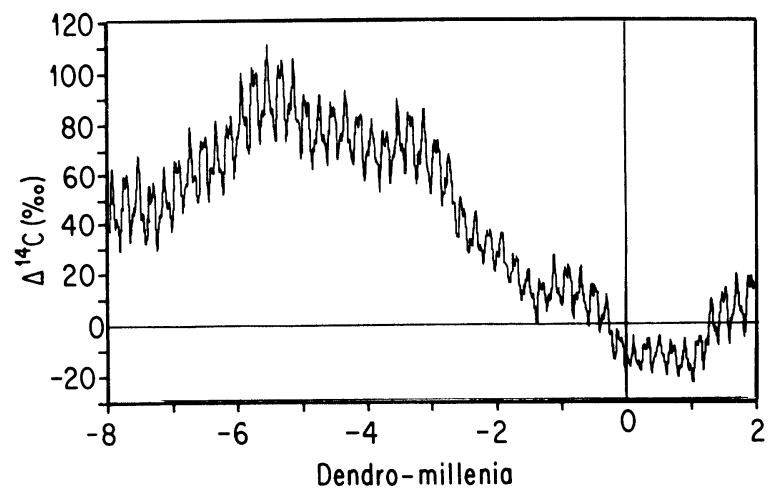

Fig 3. The simulated $\Delta^{14} \mathrm{C}$ is extended to $8000 \mathrm{BC}$. The simulation predicts another extended maximum from $5800 \mathrm{BC}-5100 \mathrm{BC}$ if the 2400 -yr non-dipole cycle is stationary. 


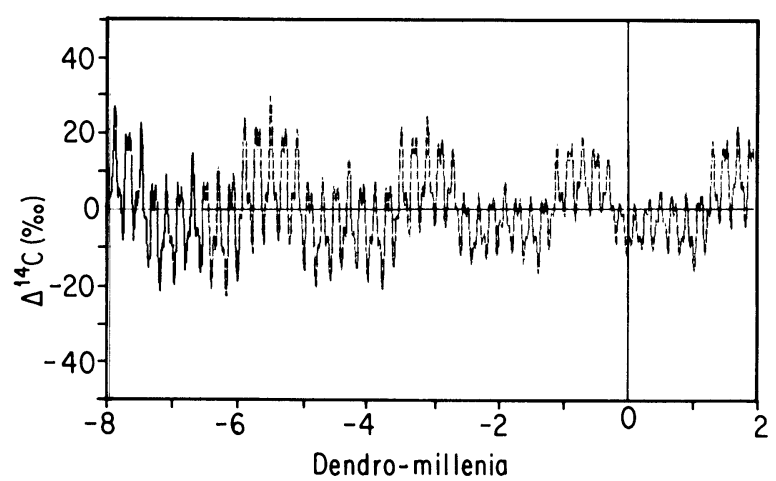

Fig 4. The simulated curve after the removal of the 11,300-yr period trend shown here probably overstates the symmetry because the 1200 -yr non-dipole harmonic is made to maximize simultaneously with every maximum and minimum of the 2400 -yr fundamental frequency. Fourier spectral analysis suggests that the harmonics are less stable than the fundamental 2400-yr period.

\section{ARIZONA HIGH-PRECISION DATA BEYOND 5350 BC}

Figure 5 shows our high-precision data for early BC time. The data lie symmetrically around the extension of the 11,300-yr sinusoid as previously indicated by Bruns et al (1983) for the south German oak data. An extended maximum occurs at $5500 \mathrm{BC}$ as predicted from the 2400 -yr westward paleomagnetic drift. This extended maximum can also be seen in the south German oak data of Bruns et al (1983, Fig 1). An extended minimum can be seen from 6900-6400 BC in the south German oak data of Bruns et al, which corresponds to the predicted minimum of the 2400 -yr cycle.

Between 6175 and 6550 BC the major minima are ca $200 \mathrm{yr}$ apart, but

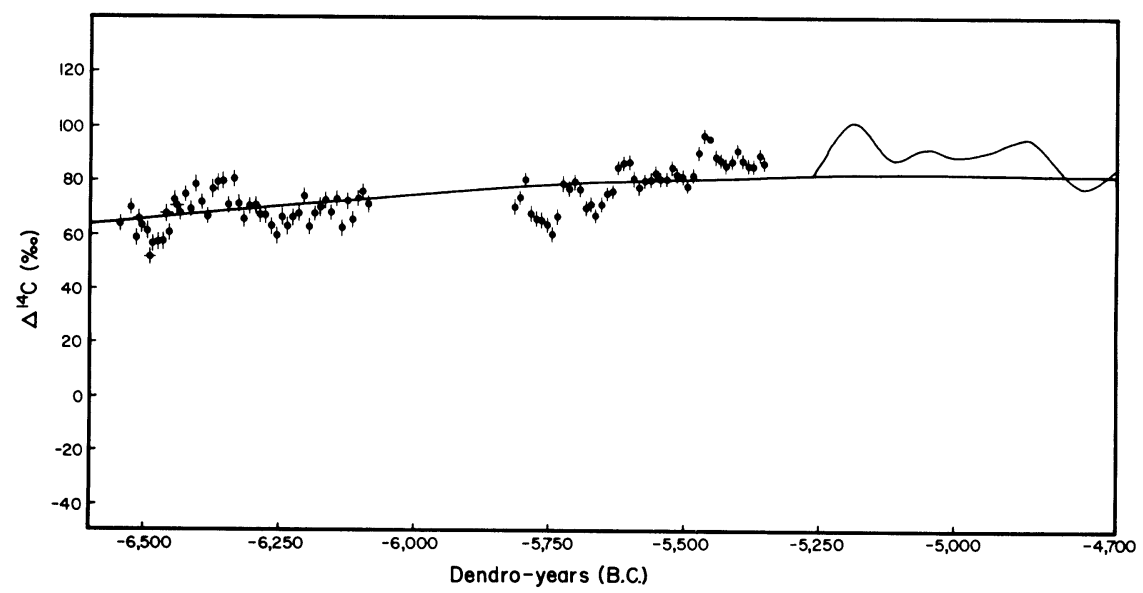

Fig 5. The 11,300-yr period trend curve based on younger data is extended to $6600 \mathrm{BC}$. Note that the new Arizona high precision data falls around the extended trend curve. The minima at 6450 and $6250 \mathrm{BC}$ are $100 \mathrm{yr}$ apart but maxima and minima are closer to $125 \mathrm{yr}$ apart between 5800 and $5350 \mathrm{BC}$. The 200 -yr solar cycle appears to be non-stationary during 
maxima and minima average closer to 125 yr apart between 5350 and 5825 $\mathrm{BC}$ suggesting non-stationarity in this time period.

\section{RADIOCARBON DIPOLE AND NON-DIPOLE MODULATION OF ${ }^{14} \mathrm{C}$ PRODUCTION}

There seems to be excellent agreement concerning the reality of solar activity modulation of the concentration of atmospheric ${ }^{14} \mathrm{C}$ both from the tree ring ${ }^{14} \mathrm{C}$ data and ice core ${ }^{10} \mathrm{Be}$ data (Beer et al, 1984). However, Beer et al reach the conclusion that

the absence of a clear long term trend in the ${ }^{10} \mathrm{Be}$ concentrations measured in the Camp Century ice core indicates that there has not been a change in the geomagnetic dipole moment large enough to significantly affect atmospheric radioisotope production rates during the last 4,000 years.

We disagree and will now reinterpret the ${ }^{10} \mathrm{Be}$ ice core data to show that the magnetic field has changed as predicted from the secular variation of ${ }^{14} \mathrm{C}$.

First, the relationship between ${ }^{14} \mathrm{C}$ production as a function of time, $\mathrm{Q}(\mathrm{t})$ is non-linearly related to the geomagnetic dipole moment, $\mathrm{M}(\mathrm{t})(\mathrm{El}-$ sasser, 1956).

$$
Q(\mathrm{t}) \propto M(\mathrm{t})^{-\alpha}
$$

where $\alpha=0.52$. Sternberg and Damon (1979, Fig 12) show that, as a consequence of this non-linear relationship, a decrease in the intensity of the dipole moment has a much greater effect on $Q(t)$ than a corresponding increase. The variation of $M(t)$ required to produce the $\Delta^{14} \mathrm{C}$ trend curve (Fig 1) is shown in Figure 6C. A $21 \%$ increase is required in $\mathrm{M}(\mathrm{t})$ between 2500 and $300 \mathrm{BC}$ to produce the required $12 \%$ decrease in production rate, $\mathrm{Q}(\mathrm{t})$. This production rate change has been transferred also to Figure $6 \mathrm{~B}$, which is modified from Figure 3 of Beer et al (1984). They chose as an initial condition "a steady state ${ }^{14} \mathrm{C}$ production rate defined by the mean value during the first $1000 \mathrm{yr}$ of the ${ }^{10}$ Be record." Thus, their simulated curve would only show the effect of the magnetic field following the termination of the steady state at $2500 \mathrm{BC}$ and would not require the long time lag which would be a consequence of a higher dipole moment in the past. They assume an attentuation factor of 4 in $\Delta^{14} \mathrm{C}$ which we accept. Thus, we would expect a decrease in $\Delta^{14} \mathrm{C}$ of $30 \%$ compared to $25 \%$ from Figure $6 \mathrm{~B}$.

Next, we consider the effect of the non-dipole magnetic field which appears to have been nearly stationary (ie, constant period and no phase shift) during the past eight millennia from its effect on the $\Delta^{14} \mathrm{C}$ fluctuation data. From the $\Delta^{14} \mathrm{C}$ date, the non-dipole field should have been a minimum at ca AD 1700 which corresponds to a large 200-yr period Maunder minimum solar peak in both Figures 1 and $6 \mathrm{~B}$. The SAIP is surrounded by an extended maximum in both figures. Figure $6 \mathrm{~A}$ is deduced from Figure 4-4 of Strangway (1970) which shows the vertical component of the nondipole field for 1945. Most important for modulation of cosmogenic isotope production are the high latitude components of opposite sign centered around $340^{\circ}$ in both hemispheres that now oppose the dipole moment. Other components are globally distributed at low to mid-latitude in such a way as to have a smaller effect on cosmogenic isotope production. We have assumed that the 2400-yr period non-dipole field has repeated 
Equivalent longitude (drift $=0.15 \%$ yr.)

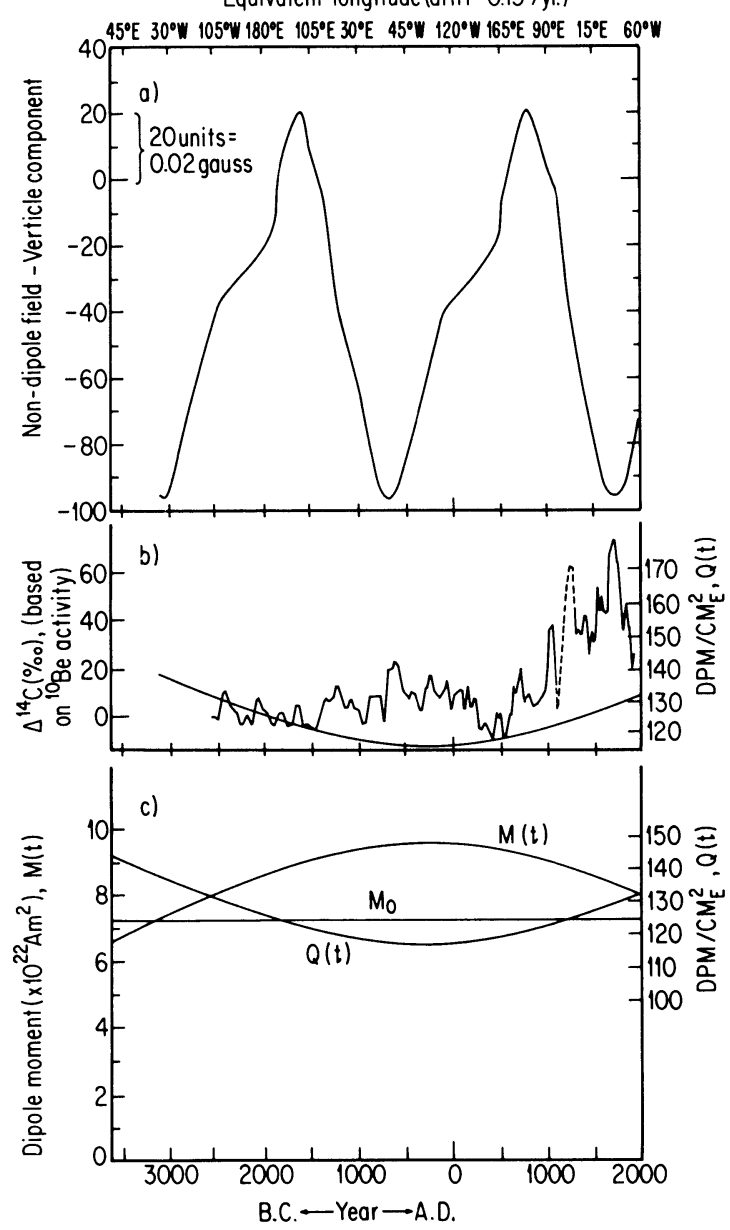

Fig 6. Reinterpretation of the ${ }^{10} \mathrm{Be}$ data from the Camp Century ice core (Beer $e t$ al, 1984) showing that ${ }^{10} \mathrm{Be}$ production is strongly modulated by the earth's magnetic field.

A. The vertical component of the high northern latitude non-dipole field which is now centered over eastern Greenland with opposite polarity to the magnetic pole. When assumed to precess around the North Pole at the same latitude and at the rate of $0.15^{\circ} / \mathrm{yr}$ westward drift (period of $2400 \mathrm{yr}$ ), it opposes and supports the north magnetic pole every $1200 \mathrm{yr}$. It would be in maximum opposition at Camp Century near the north magnetic pole at ca $700 \mathrm{BC}$ and AD 1700 causing the extended maxima of ${ }^{10}$ Be production between $1400 \mathrm{BC}-\mathrm{AD} 300$ and $\mathrm{AD}$ 1200 -present.

B. The postulated $\Delta^{14} \mathrm{C}(\%)$ variation of Beer et al $(1984)$ based on the ${ }^{10} \mathrm{Be}$ concentration in Camp Century ice. We have obtained the production rate (right ordinate) from the ${ }^{14} \mathrm{C}$ production based on the sinusoidal magnetic dipole moment required to generate the $11,300 \mathrm{yr}$ ${ }^{14} \mathrm{C}$ cycle and the present dipole moment intensity. The production rate is strictly applicable only to the dipole field, but, fortuitously $170 \mathrm{dpm} / \mathrm{cm}^{2}$ is about the production rate required by Stuiver and Quay (1980) at zero sunspot number. The dipole component is of secondary importance to the non-dipole and solar components from $2500 \mathrm{BC}$-present. Beer et al (1984) assumed no pre-2500 $\mathrm{BC}$ magnetic field variation and a steady-state magnetic field during the first $1000 \mathrm{yr}$ of the ${ }^{10} \mathrm{Be}$ record to generate the $\Delta^{14} \mathrm{C}$ curve, and, consequently, their simulated $\Delta^{14} \mathrm{C}$ curve based on ${ }^{10} \mathrm{Be}$ variations would not show the long delay (ca $1200 \mathrm{yr}$ ) observed in the directly determined $\Delta^{14} \mathrm{C}$ data. For this reason, we do not include a time lag in modeling $\Delta^{14} \mathrm{C}$. 
itself by rotating westward at the rate of $0.15^{\circ}$ per year around the pole according to this model of Lund and Banerjee (1985). The minimum of the vertical component of the non-dipole field occurs at $770 \mathrm{BC}$ and it is negative opposing the dipole field from $1400 \mathrm{BC}$ to $\mathrm{AD} 600$, producing the $\Delta^{14} \mathrm{C}$ and ${ }^{10} \mathrm{Be}$ increase during that time. The non-dipole field opposes the dipole field again from AD 1100 to the present, suggesting a causal relationship to the extended maximum around the Wolf through Maunder minima. The minimum of the non-dipole field is reached at AD 1730, suggesting that it will continue to decrease into post modern time contributing to the Suess (1955) effect and requiring caution in evaluating the fossil $\mathrm{CO}_{2}$ contribution to the Suess effect. We conclude that both the solar modulation and magnetic field effects are present in both the $\Delta^{14} \mathrm{C}$ data from tree rings and the ${ }^{10}$ Be data from the Camp Century ice core.

\section{CONCLUSIONS}

We have simulated the ${ }^{14} \mathrm{C}$ fluctuation assuming solar modulation with a period of $200 \mathrm{yr}$ and two high frequency components. The results are in accord with the conclusion of Suess (1980) concerning the existence of this solar modulation period and it seems to be nearly stationary during the last seven millennia BP but may be non-stationary in the eighth millennia BP. We have also confirmed the conclusion of Bruns et al (1983) that the 11,300-yr period trend line continues to $6500 \mathrm{BC}$. We have assumed that this trend is the result of a nearly sinusoidal change in the earth's magnetic dipole moment during the Holocene and is modulated by a strong, stationary fundamental non-dipole component of the $2400-y r$ period with less significant harmonics at periods of 1200,800 , and 600 years. The magnetic components, in turn, modulate the amplitude of the solar components which probably account for the failure of the Fourier power spectra to verify the 200-yr period between 3300 and $1000 \mathrm{BC}$. The following observations tend to support the reality of magnetic modulation:

1) Although some changes in the reservoir parameters, such as changes in ocean circulation, can produce an effect of equivalent magnitude, it is difficult to conceive of a sinusoidal effect other than that produced by a uniform process such as the oscillating magnetic dipole field.

2) Both the simulated $\Delta^{14} \mathrm{C}$ curve and smoothed $\Delta^{14} \mathrm{C}$ data confirm the modulation effect on solar cycles caused by the oscillating magnetic dipole. The amplitude of the de Vries effect (Suess wiggles) from 2600 to $1200 \mathrm{BC}$ is relatively subdued, indicating modulation by the strong dipole magnetic field; but the effect is obscured in the first millennia $\mathrm{BC}$ by the non-dipole field being superimposed on the magnetic pole but $180^{\circ}$ out of phase.

3) The 2400-yr non-dipole component of the magnetic field strongly modulates the $\Delta^{14} \mathrm{C}$ trend curve and, from its effect on ${ }^{14} \mathrm{C}$ production, appears to be stationary.

4) The 2400-yr non-dipole component also strongly modulates the production of ${ }^{10} \mathrm{Be}$ as evidenced by a clear signal in the Camp Century ice core.

5) The predicted effect of the earth's magnetic dipole on ${ }^{10} \mathrm{Be}$ produc- 
tion from $2500 \mathrm{BC}$ to the present is small and compatible with the trend of the ${ }^{10}$ Be data from the Camp Century ice core.

The magnitude of the effect on isotope production of the 2400-yr period high latitude components of the non-dipole field seems, at first sight, to be surprisingly large, but we observe that every $1200 \mathrm{yr}$ they coincide with the magnetic pole and modulate the field at the north pole by +.02 and -0.10 gauss and at high southern hemisphere latitudes by -0.1 and +0.17 gauss. The field at the north pole would be ca 0.68 gauss if the non-dipole component was zero. Thus, the effect is $-15 \%$ and $+3 \%$ of the dipole field intensity and sufficient to produce the observed effect.

Einstein is reported to have said that "God does not lie and is not a practical joker." We conclude that, if the postulated dipole and non-dipole modulation are not real, the practical joke is on us.

Note added in proof:

During the conference in Trondheim Beer et al (1986) extended the comparison of the ${ }^{10} \mathrm{Be}$ in ice cores with ${ }^{14} \mathrm{C}$ in tree rings back to the early Holocene. The extended ${ }^{10} \mathrm{Be}$ data appeared to be compatible with the ${ }^{14} \mathrm{C}$ data back to $7000 \mathrm{BC}$ and with the shielding effect of the earth's magnetic field.

Kromer et al (1986) presented data indicating an increase in $\Delta^{14} \mathrm{C}$ prior to $7000 \mathrm{BC}$ which does not follow the previous $11,300 \mathrm{yr}$ sinusoid. Such a deviation from the sinusoidal relationship is not surprising considering the drastically different climate that prevailed in pre-Holocene time. On the contrary, it would be surprising if there were no Pleistocene climate effect on $\Delta^{14} \mathrm{C}$.

\section{ACKNOWLEDGMENTS}

We thank Robert Butcher for drafting the figures and Jo Ann Overs for typing the manuscript. We benefited from stimulating conversations with Robert Butler concerning paleomagnetism. We are especially indebted to Song Lin Cheng for computer programming of the $\Delta^{14} \mathrm{C}(\% 0)$ simulation programs and Edward Wallick for performing the MEM and Blackman-Tukey Fourier power spectral analyses. This work was supported by the State of Arizona and NSF Grant EAR-8314067 entitled "The radiocarbon dipole moment: an improved model and its extension through the bristlecone pine chronology."

REFERENCES

Barton, C E, Merrill, R T and Barbetti, M, 1979, Intensity of the Earth's magnetic field over the last 10,000 years: Physics Earth \& Planetary Interiors, v 20, p 96-110.

Beer, J, Andrée, M, Oeschger, H, Siegenthaler, U, Bonani, G, Hofmann, H, Morenzoni, E, Nessi, M, Suter, M, Wölfli, W, Finkel, R and Langway, C, Jr, 1984, The Camp Century ${ }^{10} \mathrm{Be}$ record: implications for long-term variations of the geomagnetic dipole moment: Nuclear Instruments \& Methods Phys Research Sec B, v 233, no. 2, p 380-384.

Beer, J, Oeschger, H, Siegenthaler, U, Finkel, R C, Bonani, G, Hofmann, H J, Morenzoni, E, Nessi, M, Suter, M, Wölfli, W and Langway, C C, Jr, 1986, The history of solar modulation of radioisotope production in the atmosphere: a comparison of ${ }^{10} \mathrm{Be}$ and ${ }^{14} \mathrm{C}$ records, in Stuiver, $\mathrm{M}$ and Kra, R S, eds, Internatl ${ }^{14} \mathrm{C}$ conf, 12 th, Proc: Radiocarbon, this issue.

Bruns, M, Rhein, M, Linick, T W and Suess, H E, 1983, The atmospheric ${ }^{14} \mathrm{C}$ level in the 7 th millennium BC, in Mook, W G and Waterbolk, H T, eds, ${ }^{14} \mathrm{C}$ and archaeology: PACT, Strasbourg, v 8, p $511-516$. 
Burg, J P (ms), 1975, Maximum entropy spectral analysis: PhD dissert, Stanford Univ, Stanford, California.

Champion, D E (ms), 1980, Holocene geomagnetic secular variation in the western United States: PhD dissert, California Inst Technol.

Cohen, T J and Lintz, P R, 1974, Long term periodicities in the sunspot cycle: Nature, v 250, $\mathrm{P}$ $398-400$.

Damon, P E, 1970, Climatic versus magnetic perturbation of the atmospheric C 14 reservoir, in Olsson, I U, ed, Radiocarbon variations and absolute chronology: Nobel symposium, 12th, Proc: New York, John Wiley \& Sons, p 571-593.

1977 , Variations in energetic particle flux at earth due to solar activity, in White, O R, ed, The solar output and its variations: Boulder, Colorado Assoc Univ Press, p 429 448 .

Damon, P E, Lerman, J C and Long, A, 1978, Temporal fluctuations of atmospheric ${ }^{14} \mathrm{C}$ : causal factors and implications: Ann Rev Earth Planetary Sci, v 6, p 457-494.

Damon, P E, Lerman, J C, Long, A, Bannister, B, Klein, J and Linick, T, 1980, Report on the Workshop on the Calibration of the Radiocarbon Dating Time Scale, in Stuiver, $M$ and Kra, R S, eds, Internatl ${ }^{14} \mathrm{C}$ conf, 10 th, Proc: Radiocarbon, v 22, no. 3, p 947-949.

Damon, P E and Long, A, 1962, Arizona radiocarbon dates III: Radiocarbon, v 4, p 239 249 .

Damon, P E, Long, A and Grey, D C, 1966, Fluctuation of atmospheric $\mathrm{C}^{14}$ during the last six millennia: Jour Geophys Research, v 71, p 1055-1063.

Damon, P E, Sternberg, R S and Radnell, C J, 1983, Modeling of atmospheric radiocarbon fluctuations for the past three centuries, in Stuiver, M and Kra, R S, eds, Internatl ${ }^{14} \mathrm{C}$ conf, 11 th, Proc: Radiocarbon, v 25, no. 2, p 249-258.

Dansgaard, W, Johnsen, S J, Clausen, H B and Langway, C C, Jr, 1971, Climatic record revealed by the Camp Century ice core, in Turekian, $\mathrm{K} \mathrm{K}$, ed, The late Cenozoic glacial ages: New Haven and London, Yale Univ Press, p 37-56.

de Jong, A F M, Mook, W G and Becker, B, 1979, Confirmation of Suess wiggles: 3200-3700 BC: Nature, v 280, p 48-49.

de Vries, HL, 1958, Variation in concentration of radiocarbon with time and location on Earth: Koninkl Nederlandse Akad Wetensch Proc, ser B 61, p 94-102. 1959, Measurement and use of natural radiocarbon, in Abelson, P H, ed, Researches in geochemistry: New York, John Wiley \& Sons, p 169-189.

Elsasser, W, 1956, Cosmic-ray intensity and geomagnetism: Nature, v 178, p 1226-1227.

Gleissberg, W, 1965, The eighty-year solar cycle in auroral frequency numbers: Jour $\mathrm{Br}$ Astron Assoc, v 75, no. 4, p 227-231.

Houtermans, J C (ms), 1971, Geophysical interpretations of bristlecone pine radiocarbon measurements using a method of Fourier analysis for unequally-spaced data: $\mathrm{PhD}$ dissert, Univ Bern, Switzerland.

Johnsen, S J, Dansgaard, W and Clausen, H B, 1970, Climatic oscillations 1200-2000 AD: Nature, v 227, no. 5257, p 482-483.

Klein, J, Lerman, J C, Damon, P E and Linick, T, 1980, Radiocarbon concentration in the atmosphere: 8000 -year record of variations in tree rings: first results of a USA workshop, in Stuiver, M and Kra, R S, eds, Internatl ${ }^{14} \mathrm{C}$ conf, 10 th, Proc: Radiocarbon, v 22, no. 3, p in Stuiver,
$950-961$.

Kromer, B, Rhein, M, Bruns, M, Schoch-Fischer, H, Münnich, K O, 1986, Radiocarbon calibration data for the 6th to 8th millennium BC, in Stuiver, M and Kra, R S, eds, Internat ${ }^{14} \mathrm{C}$ conf, 12 th, Proc: Radiocarbon, $v 28$, no. $2 \mathrm{~B}$.

Lingenfelter, R E and Ramaty, R, 1970, Astrophysical and geophysical variations in C14 production, in Olsson, I U, ed, Radiocarbon variations and absolute chronology: Nobel symposium, 10th, Proc: New York, John Wiley \& Sons, p 513-537.

Lund, S P and Banerjee, S K, 1985, Late Quaternary paleomagnetic field secular variation from two Minnesota lakes: Jour Geophys Research, v 90, no. B1, p 803-825.

Olsson, I U, 1970, ed, Radiocarbon variations and absolute chronology: Nobel symposium, 12th, Proc: New York, John Wiley \& Sons, 652 p.

Pearson, G W and Baillie, M G L, 1983, High precision measurement of Irish oaks to show the natural atmospheric ${ }^{14} \mathrm{C}$ variations of the AD time, in Stuiver, M and Kra, R S, eds, Internat ${ }^{14} \mathrm{C}$ conf, 11 th, Proc: Radiocarbon, v 25, no. 2, p 187-196.

Pearson, G W, Pilcher, J R and Baillie, M G L, 1983, High precision measurement of Irish oaks to show the natural variations from $200 \mathrm{BC}$ to $4000 \mathrm{BC}$, in Stuiver, M and Kra, R S, eds, Internatl ${ }^{14} \mathrm{C}$ conf, 11 th, Proc: Radiocarbon, v 25, no. 2, p 179-186.

Siegenthaler, U, Heimann, M and Oeschger, $\mathrm{H}, 1980,{ }^{14} \mathrm{C}$ variations caused by changes in the global carbon cycle, in Stuiver, $\mathrm{M}$ and $\mathrm{Kra}, \mathrm{R} \mathrm{S}$, eds, Internatl ${ }^{14} \mathrm{C}$ conf, 10 th, Proc: Radiocarbon, v 22, no. 2, p 177-191.

Sonett, C P, 1984, Very long solar periods and the radiocarbon record: Rev Geophysics Space Physics, v 22, no 3, p 239-254. 
Sternberg, R S and Damon, P E, 1979, Sensitivity of radiocarbon fluctuations and inventory to geomagnetic parameters, in Berger, $\mathrm{R}$ and Suess, $\mathrm{H} \mathrm{E}$, eds, Radiocarbon dating, Internatl ${ }^{14} \mathrm{C}$ conf, 9th, Proc: Berkeley, Univ California Press, p 691-720.

Strangway, D W, 1970, History of the earth's magnetic field: New York, McGraw-Hill, $168 \mathrm{p}$

Stuiver, M, 1961, Variations in radiocarbon concentration and sunspot activity: Jour Geophys Research, v 66, p 273-276.

1965 , Carbon- 14 content of 18 th and 19 th century wood, variations correlated with sunspot activity: Science, v 149, p 533-535.

Stuiver, $\mathrm{M}$ and Quay, $\mathrm{P} \mathrm{D}, 1980$, Changes in atmospheric ${ }^{14} \mathrm{C}$ attributed to a variable sun: Science, $v$ 9, p $1-20$.

Suess, H E, 1955, Radiocarbon concentration in modern wood: Science, v 122, p 415-417. 1980 , The radiocarbon record in tree rings of the last 8000 years, in Stuiver, $M$ and Kra, R S, eds, Internatl ${ }^{14} \mathrm{C}$ conf, 10 th, Proc: Radiocarbon, v 22, no. 2, p 200-209.

Willis, E H, Tauber, $\mathrm{H}$ and Münnich, K O, 1960, Variations in the atmospheric radiocarbon concentration over the past 1300 years: Radiocarbon, v 3, p 1-4. 